\title{
26
}

\section{Production control challenges in the food and iron industry}

\author{
Hans-Henrik Hvolby ${ }^{a}$ and Jacques Trienekens ${ }^{b}$ \\ ${ }^{a}$ Department of Production, University of Aalborg, \\ Fibigerstraede 16, 9220 Aalborg East, Denmark \\ E-mail: i9hhh@iprod.auc.dk \\ ${ }^{b}$ Department of Management Studies, University of \\ Wageningen, \\ Hollandseweg 1, $6706 \mathrm{KN}$, Wageningen, The Netherlands \\ E-mail: Jack.Trienekens@alg.bk.wau.nl
}

\begin{abstract}
A comparison of the food industry in Holland with the iron industry in Denmark shows a large resemblance in several areas such as the order handling, the delivery precision and the production planning structure. The food and the iron industry are traditionally not compared, but due to the development within the food industry towards customer specific brands and the development in the iron industry towards more generic production of non-customer specific parts, the two industries are approaching the same situation. This paper discusses the development of both industries and presents similar developments within several areas: Narrowing of planning levels, new control structures and demands of future production planning systems. The paper is an extended version of a selected paper from the WG5.7 APMS`96 conference in Kyoto, Japan (ISBN: 4-915740-20-X).
\end{abstract}

\section{Keywords}

Customer relations, Production Control Systems, Production Concepts 


\section{EVOLVING CUSTOMER RELATIONSHIPS}

Currently, many changes are taking place in the area of production. These changes are initiated by developments in the market. On one hand we see an integration of different products and geographical markets into one large scale global market; on the other hand we recognise a large diversification within this market. This also reflects diversification of customer orders, not only dependent on the scale of the international and national markets, but also dependent on the politics of the individual company.

With regard to customer orders of production companies we experience greater demands for product quality and delivery time and, very important, a wider assortment and shorter life of the product. Within the production field this implies an evolution towards production processes which are based on individual customer orders.

These developments towards diversification of customer orders lead to the phenomena that quantity and frequency of sales of products in the short run are becoming more and more unpredictable for many companies. Companies try on one hand to widen their assortments, and on the other hand they try to shorten the production time, reduce the delivery time, lower the production costs etc. This means that the production process has to become more flexible in order to meet the dynamics of the market. To deal with these challenges a shift in the nature of the production control systems and the information systems supporting these is necessary. Previous studies [Trienekens 1993,1995], [Haas et al, 1995] point out that these changes are similar in both the food industry and the iron industry.

Typical products from the analysed companies in the food processing industry are canned food, dairy products, beverage products, meat products and fish products. Typical products from the analysed companies in the iron industry are machines, tools, pumps, transmission units and heavy industry products.

Because of the complexity and interrelationships of many processes in the food industry and because machine-capacities are relatively expensive, management of capacities is more important than management of the product flow. In the past the optimal use of capacities was often the key item in the planning process of these companies. Mass production based on the capacity available was common in the food industry as illustrated in figure 1. Figure 1 shows the developments in the food industry concerning both diversification of customer orders and changes in the manufacturing systems.

We see that instead of mass production (shipment) the trend is towards packing according to order. Often one single food product can be found in many different packages, depending on the wishes of the customer. This development is among others caused by the branch policies of chain stores wanting to offer a large assortment of products to the customer. [Trienekens 1995]

Materials planning in food industries used to be less important because of the insignificant critical attitude to materials. As more and more orders become customer specific, materials become relatively more important. 

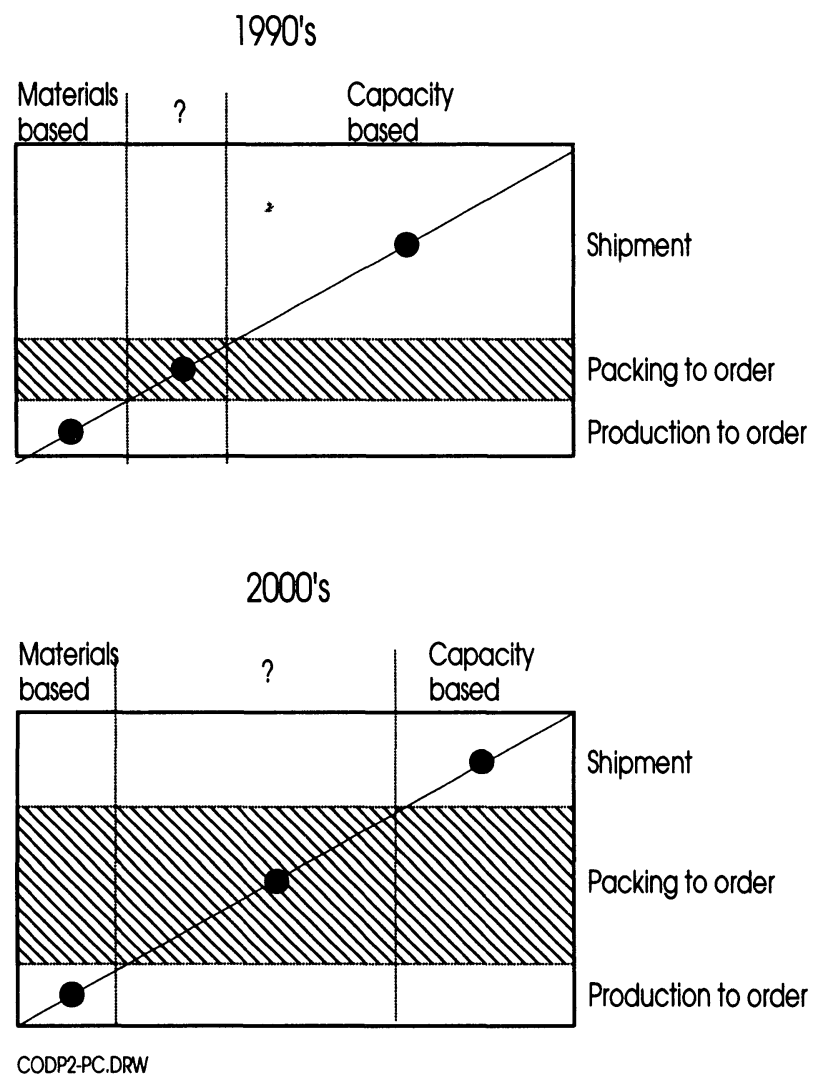

Figure 1: Status and expected change in production concepts in the food industry. Packing to order will increase at the expense of shipment (to order).

This change also influences the manufacturing systems, since the capacity oriented planning systems are unable to cope with the new situation. In many companies the scheduling function is today handled by the production floor manager by hand.

As illustrated in figure 1, the trend in the iron industry is illustrated in figure 2. The development moves towards customer specific production by means of assembly to order. In order to comply with customer demands assembly to order becomes more and more important.

The production control systems used in the iron industry are MRP based systems as regards the shipment sector and project planning systems as regards the production to order sectors. However, neither MRP nor project based systems are suitable for assembly to order. Customer orders are lost in MRP systems and materials planning is a weak part in time based planning systems. 
High costs of one-of-a-kind production on one hand, and growing, diversifying markets on the other hand point towards combined or batch production.

As illustrated in figure 1 and 2 production to stock (shipment) is still relevant for a small part of the companies.
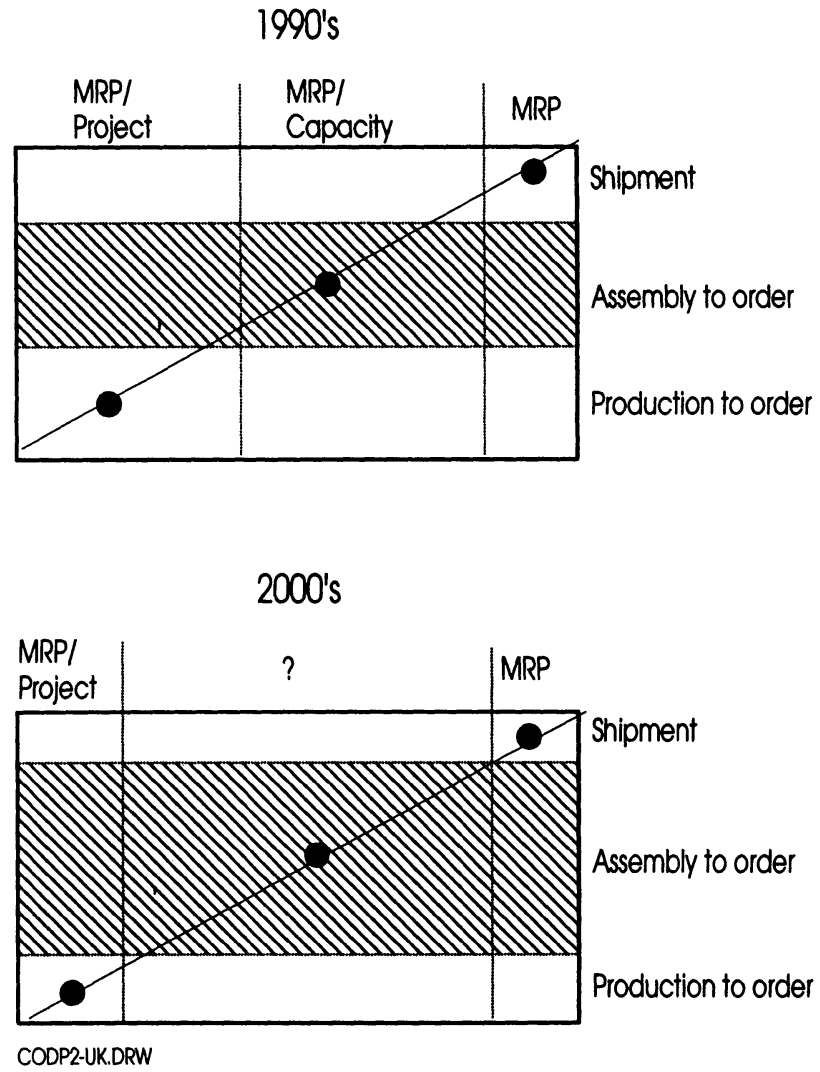

Figure 2: Status and expected change in production concepts in the iron industry. Assembly to order will increase at the expense of production to order and shipment (to order).

Also production to order in the food industry and in the iron industry continuos to play an important part for these industries. For an increasing amount of products, however, a major part of the production process is initiated by customer orders. In both sectors the customer order decoupling point seems to be moving towards the stage where products have to be assembled (in the iron industry) or have to be packed (in the food industry) to order. 
However, the production planning systems are, to some extent, unable to support this development. MRP-systems primarily handles batch production of orders in which the Bill-Of-Material is specified at the order point, while Project Planning handles the scheduling problems of orders in which the Bill-Of-Material cannot be specified at the order point. Often capacity planning is left to the shop floor - in some companies handled by separate (PC-based) capacity planning systems. This area will be discussed in the following section.

\section{PRODUCTION PLANNING SYSTEMS}

A rough classification of planning systems could lead to identifying two basic types:

- Material-based systems

- Activity-based systems

Material-based systems (MRP) have been developed to answer the demands of large scale batch production where materials are in focus, whereas activity-based systems (Project Planning) are used as a scheduling tool where the time aspects are in focus. Still MRP systems dominate the companies in Europe although a number of accepted disadvantages are present in the systems such as:

- Oriented towards production to stock

- Hierarchic decision structure based on product structures, e.g. a product made of half-fabricates which are made of raw materials.

- Top-down planning structure of several levels (year, month, days)

- No support of customer order oriented production environment

- Materials and capacity are super-optimised in separate modules without considering the interdependence between, e.g. batch sizes and capacity. [Harrison, 91]

- Poor support of managing capacities on the shop floor

The incomplete capacity planning features lead to a number of problems especially uncertainty of order acceptance. Both in the food and in the iron industry orders (especially rush-orders) are typically accepted by the foremen on the shop floor. This implies that the responsible administrative functions do not have the appropriate information system to support the decision-taking in the order-handling process. A possible solution to these problems are a division of the production in smaller units [Jensen, 96]. 


\section{SIMILARITIES IN CHARACTERISTICS AND DEMANDS ON PRODUCTION CONTROL SYSTEMS}

With respect to production planning structures the similarities in Characteristics and Demands on production control systems are divided into four areas:

- handling the dynamics of the customer order

- fine-tuning the production processes

- production structures

- lot registration and traceability

The four areas are discussed in the following:

\subsection{Demands with regard to handling the dynamics of the customer order}

The characteristics of the products and the delivery time required by the customer are often unknown until the customer order is placed. Further more different customer orders have different decoupling points as illustrated in figure 1 and 2 .

Case studies show that many companies have an accuracy in delivery of customer orders at 80 to 85 percent [Barfod et al., 96]. For most of these companies accurate delivery is vital to hold on to the customers. The inaccurate delivery is caused be several circumstances. The customisation results in an increased number of (individual) orders, which makes planning more complex. Often the specification of the customer order is not final when the order is accepted. Also the general reduction in delivery time make demands on a mere precise planning. These and other effects makes it difficult for the sales and the planning departments to have a detailed knowledge of the actual situation in the production and the consequences of accepting a customer order. Therefore many of these decisions are placed on the foremen in the production even though they have no planning tool to support the decisionmaking. The planning system and the supporting information system should be able to support the following actions:

- Delivery specifications to the customer at order entry

- Planning of customer specific recipes / products for the food industry and the iron industry

- Follow individual customer orders in the order cycle of the company 


\subsection{Demands with regard to fine-tuning the production processes}

The planning system and the supporting information system must be able to Distinguish between production according to order and production to stock of endproducts and half-fabricates. The fine-tuning is related to order conditions, customer priorities etc. Also simultaneous planning of materials (raw materials, half-fabricates and end-products; which are purchased, in stock or in the process pipeline) and capacities (the actual and the planned use) are important

Often more than one end-product comes out of one production process (e.g. from one pig a lot of different meat products can be made; several items could be made out of one metal sheet in one punch operation). The possibility of planning co-products in the production process is therefore important for both industries.

\subsection{Demands with regard to the Production Structure}

In the Iron industry we se a trend towards product factories and production groups, but within a number of companies this solution is not suitable. This goes for companies with a large number of key machines or production lines such as door and window manufacturers. These company types have almost the same problems as the process industry.

Therefore there is a need for more flexible production structures in this kind of industries as illustrated in Figure 3.

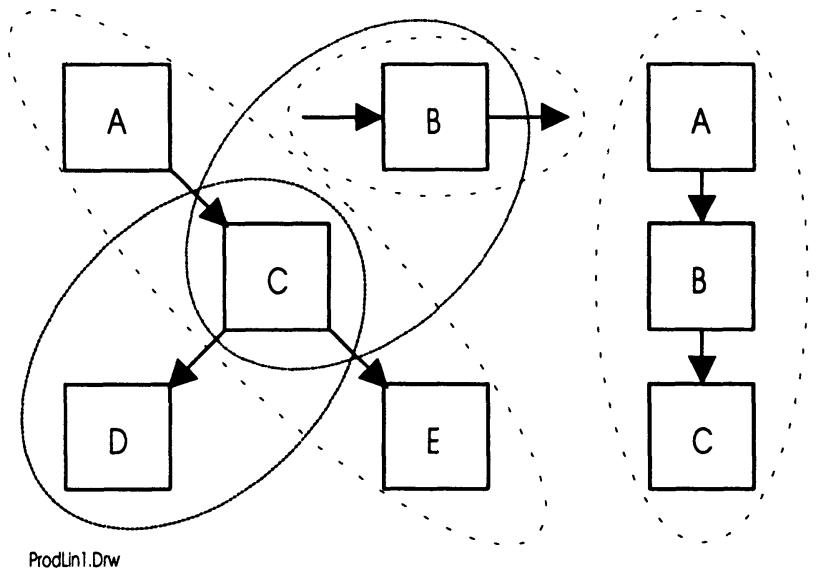

Figure 3. The figure illustrates the development from a fixed production line (on the right) towards a very mixed production flow (on the left) due to the increased number of product variants. The situation is most apparent in the process industry and in the flow-oriented parts of the iron industry. 


\subsection{Lot registration and traceability}

A final feature is that lot registration and traceability become of key importance in both industries. Within a few years traceability will be required by law in the food industry. In the iron industry the advantages of traceability are most visible when servicing products, e.g. the ability to provide the customers / technicians with the proper spare parts.

A company producing baby-food had to withdraw all products from the store because a sample showed remains of a cleaning fluid in the food. If the company had been able to trace the products of the single batches (from the production to the customer) only the affected batch had to be withdrawn from the stores and the economic consequences and discredit could have been reduced to a minimum. Not only the ability but also the velocity of the tracing process is very important in this respect.

Yet another example is a company producing welding machines which are sold throughout Europe. The products are currently improved without changing the product identity and without tracing the batches and the used Bill-Of-Material. The service organisation is not able to identify one variant from another without analysing the components of the welding machine. This makes service a complicated matter and often the technician has to visit the customer twice to finish a repair.

\section{NARROWING AND INTEGRATION OF PLANNING LEVELS.}

Most companies have three planning levels. The highest level involves the management. At this level decisions on aggregate materials (mainly contracts with suppliers) and capacity planning, investments, personnel policy etc. are made. Most decisions are long term decisions. At the second level the production planning takes place. Customer orders are received and the need for materials and capacity to cover both customer orders and stock orders are calculated. At the lowest level the scheduling of work orders takes place. Here especially planning of capacities is of importance.

By comparing case studies of both the iron and the food industry it appears that there is a similarity at the second level. In many companies the production plan from the planning department are handed over to the shop floor even though the shop floor does not use the plan at all. The primary reason for this is that the production plans do not comply with the actual production on the shop floor. Therefore the foremen make their own "narrow" schedule (narrow in the sense that the consequence in the remaining processes are not taken into account). This leads 
to "synchronisation" problems in the other processing areas as components are delayed.

Central-oriented planning systems like OPT have focused on making a optimised plan involving all production areas in which bottlenecks, throughput time etc. is considered. However, these systems have had little success in Denmark and Holland as they require detailed information regarding process- and set-up time information which is changeable in a customer oriented production environment.

Because of the increasing importance of the ability to follow the customer order in the process (uniqueness of the order, traceability in for example the food industry) the grouping of several customer orders in batches may be taken care of at the lowest level. Indeed at this level flexibility of customer orders is best possible.

In most companies a quite strict distinction between the sales and the production department exists. Often the sales department accepts customer orders even though the production department cannot meet the requirements (product characteristics, quality, delivery time). The result is to work overtime in the production, to exceed delivery times to the customers etc. What we are looking for is an integration of production planning functions for the shop floor and to plan and to give priority to customer orders in the sales department.

In order to make a reliable plan we have to involve both the sales department and the foremen in the planning process. This could be done by making the sales department responsible for meeting the due dates of customer orders, e.g. by handling capacity planning at a rough level. Also planners could be moved to the shop floor. Both actions would narrow the levels in planning structure and thereby remove some of the existing barriers in the companies. Furthermore a possible reduction of non-value activities are identified in several case-companies.

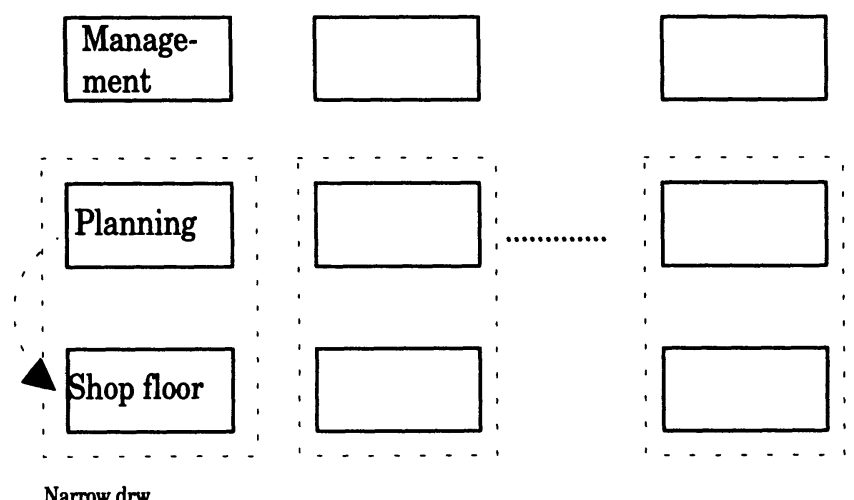

Figure 4: Narrowing of planning levels. The 'planning level' has to move towards the shop floor in order to improve the shop floor planning 
The following example illustrates an attempt of narrowing the planning levels in a large Danish company.

A Company producing large engines and gearboxes experienced a very complicated flow of materials. Complex products, many transports and much handling made the planning complicated. A lot of special materials and components were used in the production and assembly making the purchase function vital in order to secure the delivery dates. The purchase function was therefore included in the order acceptance / negotiation phase.

The planning function was split into a central and a local level. The two levels communicated with the responsible purchaser and foremen.. A detailed plan was made in conjunction with the purchasing department. The plan was passed on to the planners, which were seated in the workshop together with the foremen. These planners maintained the firm plan in conjunction with the foremen and reported to the central planning function in case of deviations or problems. /Hvolby et al, 1994/

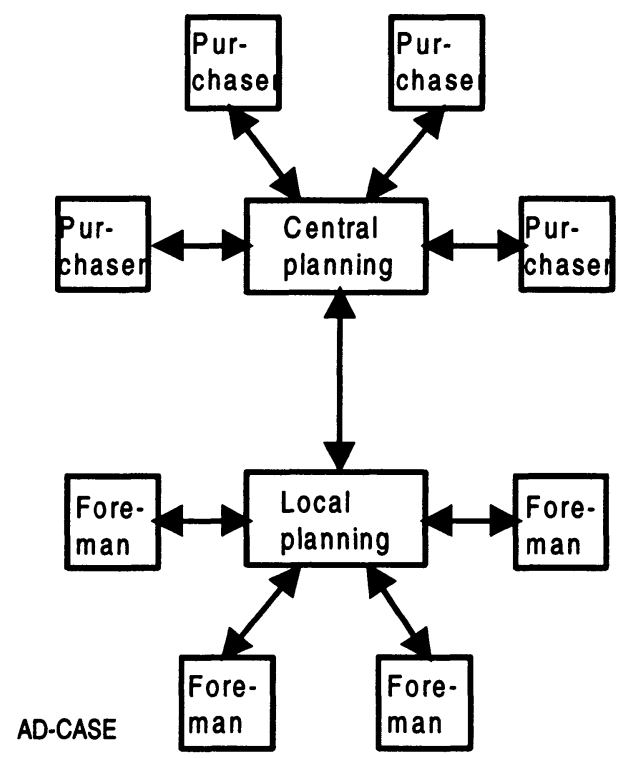

The example illustrates a possible solution of integrating the planning level with the shop floor level and thereby improving the synchronisation of orders, materials and capacity.

\section{CONCLUSIONS AND FURTHER RESEARCH}

There are a number of similarities between the developments in the food industry and the iron industry:

- the trend is towards production of half-fabricates to stock and packing or assembly to order 
- to support this the sales and the production planning function have to integrate with the staff at shop floor level

- integrated scheduling of materials, capacities and customer orders become a key issue in production control

The changing control structures in the food and the iron industry do have similar implications for the way the companies are managed and for the construction of the planning and information system.

The exchange of real time information and simultaneous planning of production to order and production to stock, integrated with the planning of sales and purchasing become essential. On the shop floor computer networks, integrated scheduling tools and a database management system linked with the companies administrative systems, have to support the modern control structures of the companies. Integration and flexibility in production control become the key issues in production control of the 2000's in both the food industry and the iron industry.

Furthermore analogies to other industries such as wood, plastic, electrical etc. could be relevant to analyse, as the dynamics of the markets effects not only the iron and the food industry.

Because of the integration of the former hierarchical and functional divided levels in the organisation and the importance of flexible production methods, we notice a trend towards cross functional tasks, e.g. the sales and production planning function, and self responsibility in multi functional teams, which improves flexible answers with regard to customer orders.

Further research must focus on:

- Order control (handling)

- New ways of working

- New ways of managing

- New information system architectures

to answer the dynamics of the market.

\section{REFERENCES}

Barfod, Ari; Hvolby, Hans-Henrik. Order Management. Industriens Forlag, Copenhagen, Denmark, 1996. (In Danish)

Bertrand J.W.M., J. Wijngaard, J.C. Wortmann. Production Control, a Structural and Design Oriented Approach. Elsevier. Amsterdam, 1990.

Burbidge J.L. Production Control: a Universal Conceptual Framework. Production Planning and Control. Vol 1, no 1. 
Jensen, Morten Guld. A Product-Oriented Production Structure in order to decentralise the Planning Tasks. Proceedings of the IPS conference in Fuglsoe, April 1996.

Haas, Henning de; Hvolby, Hans-Henrik. A Holistic and situational approach for effective Production Planning and Control. Proceedings of the Prosem '95 conference. Molde, Norway, May 1995

Harrison, Mike: Finite Scheduling in Perspective. BPICS Control, December '92. Hvolby, Hans-Henrik; Højbjerre, Per: "A More Flexible Planning Architecture for Centralised and Decentralised Planning". Proceedings of IFIP WG 5.7 Working Conference, Gramado, Brazil, 1994. ISBN/ISSN: 0-444-81910-x.

Trienekens J.H., Trienekens J.J.M. Information systems for production management in the food processing industry. Processings of the IFIP WG 5.7 - APMS '93. Greece, Athens, 1993.

Trienekens J.H., Meijs C. Key Quality Characteristics of Logistic Information Systems in Changing Business Environments. Processings of SQM 95 conference in Sevilla, Spain. Eds. M.Ross et al. Computational Mechanics Publications Vol 1. Southampton UK, 1995.

\section{BIOGRAPHY}

Hans-Henrik Hvolby received a M.S. degree in management systems from University of Aalborg, Denmark in 1984. From 1984 to 86 he worked as a planning engineer with Aalborg Boilers. From 1986 to 89 he was a researcher at the Department of Production at University of Aalborg, and in 1989 he received a $\mathrm{Ph} . \mathrm{D}$. degree with the title "Information Systems for Production Planning and Control". From 1989 to 93 he worked as an assistant Professor at the Department of Production, interrupted by a leave from 1990 to 1992 where he worked as a project Manager with F.L. Smidt. Since 1993 he has worked as an associate professor at the Department of Production, Aalborg University. His working areas are production planning and control, order management and information systems.

Jacques Trienekens received his degree in geography from Nijmegen University, the Netherlands in 1984. He worked as a researcher at a public welfare organisation until 1986. After that he worked as a consultant on information systems and management at a public health organisation, was a lecturer in information systems at the Open University and lecturer in information systems at an institute for higher economic education. Since 1991 he has been an assistant professor at Wageningen Agricultural University, department of Management Studies, in the Netherlands. His research interests include information systems and logistic management. 